\title{
Looking ahead to a future with Alzheimer's disease: Coping with the
}

\section{unknown.}

The conceptualisation of Alzheimer's disease as an illness with 'no future' exposes people with the condition to significant fear and stress. Therefore, exploring how people look ahead to the future in the face of Alzheimer's disease is of foremost importance. Semi-structured interviews $(n=14)$, explored future outlook of people with early $(n=5)$ and late-onset $(n=7)$ Alzheimer's disease and those who support them $(n=14)$. Thematic analysis identified how participants managed their changing futures through focusing on positive information, and taking 'one day at a time'. Younger and older people shared similar future outlook and subsequent coping strategies, as predicted by Socioemotional Selectivity Theory (Carstensen, 1991). Both people with Alzheimer's disease and those who support them avoided looking far ahead as a way of managing the uncertain future, and had little awareness of future planning in the context of current policies. Such avoidance suggests that policy which encourages future planning should consider its utility and explore ways of helping people to plan, whilst focusing on daily living. 


\section{Introduction}

Loss of future is a widely held stereotypical assumption relating to Alzheimer's disease in public discourse (McParland et al., 2012). In contrast to this, there is a drive towards early diagnosis as a facilitator of future planning (Dubois et al., 2016). Implicit to future outlook is people's ability to look ahead to a time where symptoms of the condition may be worse. The ability to 'mentally time travel' (Tulving, 2005) and simulate future events requires flexibly bringing together details from the past (Schacter et al., 2007). This is indicative of a specific core brain system (Buckner and Carroll, 2007), particularly for episodic memory (Abram et al., 2014). The effort required or 'cognitive load' for imagining future events (Schacter et al., 2013) suggests people with Alzheimer's disease may have difficulty with looking ahead, particularly to unfamiliar futures (De Vito et al., 2012). In support of this, research including older adults and people with Alzheimer's disease found that the ability to imagine future events is correlated with memory deficits (Addis et al., 2009; Schacter et al., 2013); as explained by the additional complexity of recombining stored information (Schacter and Addis, 2007).

Expanding on the neurological literature to consider a more holistic perspective, Szpunzar and Schacter (2013) found that if people repeatedly simulated a personal event in their future, it increased the subjective plausibility of that event taking place. Similar responses can be seen where people avoid topics such as death, through fear that it will make death more imminent (Kirshbaum et al., 2011). These findings could have a significant impact on people with Alzheimer's disease and those who support them. Imagining a future which is stereotypically very negative, and involves an increasing need for care (Chenoweth et al., 2009) may make this potential future feel more likely. 
This could have a significant emotional impact in terms of distress and despair (Kristiansen et al., 2017). Therefore, people affected by Alzheimer's disease may be cognitively able to look to the future but deliberately avoid it; contrasting with policy expectations which support early diagnosis to allow for future planning (Department of Health, 2015; Pot and Petrea, 2013; Scottish Government, 2013).

\section{Looking ahead with a time-limiting illness}

Looking to the future as a concept can be labelled in many different ways within and between disciplines. Labels of 'mental time travel', 'imagined futures', 'care planning', and 'future selves' among others have all be used to encapsulate aspects of future planning. The term 'future outlook' was coined for this research for the purpose of not limiting focus to care, and to be inclusive of shared experiences of the future. Throughout this paper, 'future outlook' refers to the potential futures people with dementia and their supporters may experience in the short term, and longer term.

Future outlook allows people living with dementia to plan ahead and reduces the risk of people making decisions in 'crisis point' moments (Ramsbottom and Kelley, 2014; Sinclair et al., 2016). However, if future outlook is to be encouraged (as in various dementia strategies, Department of Health 2009, 2015; Scottish Government 2017), it is imperative to be aware of how people look ahead with a time-limiting ${ }^{\mathrm{i}}$ illness. The term 'time-limiting' has been used as an alternative to 'life-limiting' due to the main theoretical frameworks conception of time (Lockenhoff and Carstensen, 2004). Additionally, the focus on time sought to move away from unintended associations with 
capabilities and quality of life associated with the term 'life limiting' (Entwistle and Watt, 2013).

Examples of research exploring such future outlook include Small and Rhodes (2001) who found that people who were seriously ill were reluctant to think about future needs; instead they preferred to focus on 'one day at a time'. Similarly, Brown and Graaf (2013) observed that people facing high levels of vulnerability and uncertainty due to the progression of cancer, were more likely to focus on the day-to-day present than the future. This was particularly evident when people did not feel in control of their condition.

The trajectory of Alzheimer's disease is unpredictable (Doody et al., 2010), and therefore difficult to control. When control is taken away, it is more adaptive to focus on situations that you can have mastery over (Brown and Graaf, 2013). For example, manage the unpredictability by focusing on the near future, and 'bracketing away' the negative outcomes which may lie further ahead (Brown and Graaf, 2013). Such strategies may be particularly useful in cases such as Alzheimer's disease where the progression of the condition leads to an inevitable difficult future in terms of a decline in independence and increased care needs (Feldman et al., 2005; Jalbert et al., 2008).

This article explores whether similar findings are seen for people affected by Alzheimer's disease. Research highlights that the progressive nature of the condition and the complex interaction of biopsychosocial factors makes the experiences of people affected by dementia and their supporters unique (Karg et al., 2018; Samsi \& Manthorpe, 2014), 
however, commonalities in adjusting to experiences have been seen in comparisons such as dementia and cancer (Gillies and Johnston, 2004).

From a theoretical perspective, Socioemotional Selectivity Theory (SST; Carstensen et al., 1999) hypothesises that both older people and people who are experiencing 'timelimiting' conditions will have similar views of the future (Lockenhoff and Carstensen, 2004). 'Time-limiting' has been used over the more commonly used term 'life-limiting' as there is an implicit assumption within 'life-limiting' that your quality of life will be diminished. 'Time-limiting' reinforces the underlying premise of SST, where time is the key factor in differences between people. SST predicts that a restricted sense of time results in a pursuit of 'emotion focused' goals. Such goals lead to people being more likely to focus on each day at a time, optimising resources to focus on meaningful experiences, over gathering knowledge for the future (Lockenhoff and Carstensen, 2004).

The pursuit of positive emotional experiences in the face of difficult circumstances poses an interesting phenomenon (Sharot, 2011). For example, how people manage negative attitudes and beliefs towards Alzheimer's disease, and look to a future which is stigmatised solely as 'care'. Socioemotional Selectivity Theory suggests that to remain positive, the smaller things in life become appreciated (Hicks et al., 2012). Most importantly the relationships with those around us are prioritised, due to the pursuit of emotionally engaging experiences (Benbow and Jolley, 2012; Carstensen, 1991).

Finally, it is important to understand how supporters view the future given the increased responsibility placed on them, particularly in future planning and decision making when capacity is questioned (Poole et al. 2018; Livingston et al. 2010). 'Supporter' has been 
Future Outlook and Alzheimer's Disease

chosen instead of terms such as 'carer' or 'caregiver' (Molyneaux et al., 2011) to reflect preferences of supporters (O’Connor, 2007). Of particular interest is how supporting somebody with Alzheimer's disease influences a supporter's future outlook. Socioemotional Selectivity Theory (Carstensen, 1991) predicts that younger supporters would not see time as restricted, whereas older supporters would be more likely to see time as restricted. Alternatively, the combined futures of people living with Alzheimer's disease and their supporters may result in a shared experience of restricted time seen across age groups. Therefore, supporters of people with early and late-onset Alzheimer's disease may employ the positive bias and focus on emotion-focused goals.

Overall, the literature highlights several unanswered questions in relation to future outlook and Alzheimer's disease including, whether looking ahead is physically possible for people with Alzheimer's disease, due to the cognitive load of combining information; whether future outlook is influenced more by age or the presence of Alzheimer's disease as explored through the lens of socioemotional selectivity theory; and whether the intertwined futures of people with Alzheimer's disease and their supporters results in similar future outlook perspectives.

\footnotetext{
Aim

The aim of this research was to explore future outlook of people with early and late-onset Alzheimer's disease and their supporters. A qualitative approach using semi-structured interviews focused on how people coped with looking to the future with a time-limiting illness.
} 
Future Outlook and Alzheimer's Disease

\section{Methods}

Participants

People with Alzheimer's disease and their supporters were sampled using purposive sequential sampling from Neuroprogressive and Dementia Network register

supplemented by two NHS referrals. All participants lived in Scotland and spoke English. For inclusion into the study, people with Alzheimer's disease were categorised as having mild-moderate symptoms on the Neuroprogressive and Dementia Network register, and all had capacity to consent with the model of process consent (Dewing, 2007) applied throughout. 'Early-onset' was defined as people diagnosed under the age of 65 years old; 'Late-onset' was defined as people diagnosed over the age of 65 years old, in-keeping with UK-based clinical parameters (Koedam et al., 2010). All participants needed to have a study partner due to the research aim including both people with Alzheimer's disease and their supporters. Of note, 11 of the 14 supporters were spouses with only 3 being adult-children, despite the reported prevalence of this caring role in literature (Brodaty and Donkin, 2009).

\section{Design}

The qualitative research design was part of a mixed-method doctoral research study. As such, all participants had previously completed questionnaires around perceived stigma Ashworth (2017) with the researcher between 3 and 6 months before the interviews discussed in this paper. Results have been presented separately to allow more in-depth focus on the main findings. 
Fifteen dyads were invited to be interviewed (7 early-onset and 8 late-onset), of which one dyad declined (Stewart and Jean/ PE2 and SE2). Participants were offered the choice or having the interviews together or alone, with the priority being that participant's felt comfortable and able to have their voices included. Overall, semi-structured interviews exploring future outlook took place with 12 joint interviews with people with Alzheimer's disease (5 early-onset: 7 late-onset) and their 12 supporters (5 early-onset: 7 late-onset). Two interviews were with supporters only (Katie (SE3) and Michael (SL2), see table 1) due to the person with Alzheimer's disease having reduced capacity and difficulty engaging in more in-depth interviews. Of note, the inclusion criteria for the study was for people with Alzheimer's disease and their supporters to both take part. However, if the person with Alzheimer's disease or supporter needed to discontinue the study once consented and the other person wished to continue, they could do so.

\section{< Insert Table 1 about here >}

A topic guide for the interviews was devised to address gaps in the research literature and the overall aim of the study. Topics included feelings of control (i.e. how do you feel about managing Alzheimer's disease?); knowledge of advance care planning (i.e. have you thought about future care?) thoughts about the future (i.e. have your thoughts about the future changed since your diagnosis?), and hopes and fears (i.e. do you have any particular hopes and fears about Alzheimer's disease and the future?).

All participants consented to interviews being audio-recorded. Interviews took place in people's homes, and included additional time for sharing a cup of tea (Ashworth, 2014) and informal conversation to build relationship and encourage the indirect benefits of 
research (Higgins, 2013). Ethical approval was granted by an NHS research ethics committee followed by site-specific approval across five health boards (NHS Forth Valley, Greater Glasgow and Clyde, Lothian, Grampian and Tayside).

\section{Analysis}

Interview data were analysed using thematic analysis following the guidelines set out by Braun and Clarke (2006). Audio-recordings were transcribed by the researcher. An initial code book of 11 a priori codes was applied to reflect the research questions and available research literature including coping, relationship change, reaction to diagnosis, and changing futures. Transcripts were read through multiple times and separated by age of diagnosis (early or late-onset) for exploration of possible differences. New codes were added throughout including role change, planning, day at a time, and uniqueness. Data with multiple codes was either allocated a singular code upon further revision, or kept across multiple codes. Potential themes were considered based on the collation of codes, as discussed by Braun and Clarke (2006), see Table 2. The themes were then reviewed to reflect both the chunks of data and the entire data set. Once themes had been identified and refined, they were named and prepared for reporting (Braun and Clarke, 2006). Throughout the analysis process doctoral supervisors reviewed samples of transcripts and the assigned codes. Clearly documented 'audit trail' (Shenton, 2004) of shared reflections increased the transparency of the process and therefore the quality of the analysis (Moravcsik, 2014). Group consultation of themes increased 'trustworthiness' through conformability and dependability (Vaismoradi et al. 2016; Bryman et al. 2008) and confidence in data saturation (Mason, 2010). The analytic process was supported by QSR International's NVivo 10 Software. 


\section{$<$ Insert Table 2 about here >}

\section{Results}

Thematic analysis of the semi-structured interview generated two overarching themes in relation to people's future outlook: 'adjusting to changing futures' and 'maintaining positivity one day at a time'. These themes encompass several sub-themes which are highlighted in figure 1 and will be discussed throughout the following section. There is not equal weighting between the global themes; maintaining positivity by taking one day at a time was the clear focus for future outlook among people with dementia and their supporters. Comparatively, adjusting to changing futures is more heavily weighted towards supporters and the process they have gone through to support the participants with dementia to continue as 'normally' as possible.

\section{$<$ Insert Figure 1 about here >}

\section{Adjusting to changing futures}

The development of Alzheimer's disease inevitably led to changes in peoples' lives. The first theme 'adjusting to changing futures' encapsulates these changes, and is built up of three sub-themes, 'practical changes', 'restricted autonomy' and 'anticipated retirement'. Changes in health can restrict a person's ability to continue in the same way as before such change. For people affected by Alzheimer's disease, change was particularly evident around the occupation of the person with the condition or their supporter; driving; and lifestyle choices. For all of those who had to make changes in these areas, there was a 
clear sense of loss and uncertainty about how this would affect their lives, noting both the change in independence and fearing boredom from not being busy.

\section{'Practical Changes'}

Part of future outlook for several participants was demonstrated when making practical adaptations around their homes. Potential change in the future which may increase need was pre-empted to help it feel more manageable. In doing so, they highlight a clear awareness of potential challenges ahead but show a preference to minimize the focus on this. For example, Sophie (SL15) had moved their bedroom downstairs to reduce the risk of Angus (P15) struggling with the steps; however, she talked frankly about how hard this was to do due to the restricted space and the emotional impact of having to leave the bedroom they had shared:

"I was saying to one of the ladies I was thinking of moving the bedroom downstairs... but there was an awful lot against us moving downstairs, for a start the bedrooms tiny, can't take our bed down... you get so used to everything... there's an awful lot of things folk don't understand unless you're actually working with others, nobody can say what you can and can't do." (Sophie, SL15)

It was evident that such changes made it harder for participants like Sophie (SL15) to avoid the increased needs of the person they support. Lucy (SE5) had renovated the kitchen, noting how much they tried to keep it similar to before to reduce potential future disorientation for Murray (PE5). In addition, Lucy (SE5) and Murray (PE5) had bought a 
summer house to allow Lucy (SE5) her own space, whilst knowing that Murray (PE5) was happy in the familiar environment of the home.

“...this is where Murray feels comfortable, and if I need to just get away, I've got my wee [little] summerhouse... so that's me thinking ahead all the time, because I know and gauging what's happening, we're just gonna need our space but we want Murray to be safe, so the stuff in the kitchen I'm trying to think how can I get it so that it's as similar as it was before..." (Lucy, SE5)

Similarly, Michael (SL2) spoke about renovating an unused space to become a selfcontained studio for 'formal carers' to stay if Grace (PL2) needed more continuous care. These bigger changes showed awareness of the potential challenges, and pre-empting change in the future to find practical ways to deal with them. However, there was a lot more 'detachment' from these discussions shown through conversation repeatedly returning back to the idea of 'it could be worse' or 'it might not be necessary', compared to other areas of the interview. The emphasis on 'practical changes' by pre-empting future need was largely centred on supporters and their increased responsibility to make decisions, whereas people with dementia favoured a more active avoidance approach which is discussed more within the second global theme.

\section{'Restricted Autonomy'}

In addition to pre-empting possible futures by making 'practical changes', there were clear changes taking place in the present affecting how autonomous people with Alzheimer's disease felt. All but one of the participants with early-onset Alzheimer's disease discussed the loss of their driving license and the impact this had on their 
Future Outlook and Alzheimer's Disease

confidence and feelings of independence. Both Matthew (PE7) and Jack (PE6) talked about how they had been driving all of their lives, and having this taken away had caused significant distress over how it might affect future activities as highlighted in the conversation between Jack and Olivia (SE6),

"I've drived all my life and then..." (Jack, PE6)... "Aye, but he dinnae feel confident to drive" (Olivia, SE6). [Yes, he does not feel confident driving]

Unlike the other participants with early-onset Alzheimer's disease, at the time of interview Murray (PE5) was still driving but waiting to find out if his license was to be renewed. Discussing the impact of this possibility further illustrated how much these participants saw driving as part of who they are, and a symbol of their independence. Comparatively, driving was very rarely mentioned in the interviews with people affected by late-onset Alzheimer's disease, other than references from supporters highlighting that they appreciated still being able to drive. For example, Poppy (SL1) notes how her ability to drive kept her optimistic,

"A lot of friends can't drive, and that would be awful, and I thought right you can drive and that's a positive from there.” (Poppy, SL1)

All of the people with dementia and the majority of supporter's were no longer in employment; although changes in employment were largely discussed by people with early-onset Alzheimer's disease. Occupational status had clear impacts on how people 
with early-onset Alzheimer's disease viewed themselves and considered their plans for the future. Both Jack (PE6) and Murray (PE5) talked about how they had to leave work due to fears such as burdening colleagues, or no longer feeling capable of maintaining the standard necessary. It was also particularly evident for Murray and Jack how important colleagues' reactions to their diagnosis were to them, particularly in treating them the same,

“...There's 18 years in my work, and when they found out about it, they come up and shook my arms, worst of luck, wee laugh, wee joke, come on Jack, so I was always Jack...” (Jack, PE6)

Adjustment to change in occupational status was also difficult if people did not feel leaving work was necessary, for example Charlie (PE4) felt frustrated by not feeling 'allowed' to work as shown by the conflict between himself and Emma (SE4),

"I doubt if you could of [carried on working] now could you? You couldn't wire up tools and use a computer?" (Emma, SE4)...

"Oh well, I don't know" (Charlie, PE4)...

"Be honest Charlie, I mean, I know you would like to." (Emma, SE4)...

"I would have a go at it anyway...I was a [job title] for goodness sake, I used to do that every day" (Charlie, PE4). 
Future Outlook and Alzheimer's Disease

Despite this tension, Charlie was adamant that the difficulties he had faced due to the condition did not bother him, exemplifying the positivity-focused coping style that will be expanded on in the second theme:

“It doesn't bother me Emma, honestly, it doesn't bother me at all" (Charlie, PE4)

As well as the change in the person with Alzheimer's disease's employment status, supporters such as Katie (SE3), Lily (SL3) and Poppy (SL1) had given up work to help Toby (PE3), Harris (PL3), and David (PL1),

"Well I was working before...I took early retirement with a view to getting a parttime job ... but I don't have time for that." (Lily, SL3).

Lily had taken early retirement and planned to work part-time but was unable to do this given the circumstances. For both Katie (SE3) and Lily (SE4), losing this employee role had a clear impact, affecting their confidence and feeling of connection. Unlike the other supporters, Lucy (SE5) was still in employment and it was evident how important maintaining this for as long as possible was for her, as shown by the following extract,

"I would hate at this point in time to be retired and with Murray (PE5) 24/7, because we would drive each other mad, I, I currently still need my job, I still enjoy working, most of my, my colleagues who are my age have gone, so I'm one of the most senior ones there now...." (Lucy, SE5) 
The interviews highlighted that following the diagnosis of Alzheimer's disease, people had to adapt to the losses associated with the condition. This process was particularly evident for people affected by early-onset Alzheimer's disease, as they were more likely to have been in employment prior to disease onset. Further, changes were not seen in isolation but were shared by supporters individually and in their shared relationship.

\section{'Anticipated Retirement'}

Discussion around expected retirements and the changes associated with Alzheimer's disease are captured within the sub-theme 'anticipated retirement'. When considering age differences, several participants commented on how as a younger couple they did not get to have a 'proper retirement' whereas older people had. For example, Olivia (SE7) explains

"Your future's been snatched away, your plans have grandly altered, and where the elderly, the over 75s, they've had that time" (Olivia). "We're nowhere near it yet." (Matthew, PE7).

Similarly, Emma (SE4) felt Charlie (PE4) was lucky to have taken early retirement prior to the onset of Alzheimer's disease, lessening the feeling shared by Olivia that retirement was lost,

"You wouldn't have had a great retirement, because you finished work early...you've had a good few years" (Emma, SE4) 
Despite the apparent age-related differences, the feeling of lost futures or lost retirement is not exclusive to people affected by early-onset Alzheimer's disease. Michael's (SL2) frank discussion about his future supporting Grace (PL2) exemplifies this,

"Well I often think, believe it or not, that is this it? Is this all I can expect out of my life for the next, I don't know how many years I might have. Can I slip away and enjoy what's left of my life, since I've already devoted a lot of years to her? And can I slip away and just live the way I want to do?" (Michael, SL2)

Despite hypothesising about a time where he could separate his future with Grace (PL2), Michael goes on to share how he would never want to do so as he would not be able to cope without her. The entwined futures based on relationships is demonstrated in Jennie's (SE7) statement,

““It didn't just happen to Matthew, it happened to me too." (Jennie, SE7)

Similarly, the shared futures can be seen when Katie talked about how Toby (PE3) was no longer able to participate in the same things as she was,

"I feel guilty that...I'm looking forward to going to somewhere I've not been, I do feel guilty because we never went there together." (Katie, SE3) 
The experiences of participants, particularly supporters, in relation to anticipated retirement illustrates how people can experience a sense of loss for what could have been, and raises potential challenges in helping people to adjust their view of retirement in the face of Alzheimer's disease. The experiences shared by supporters' highlights the entwined futures of people with Alzheimer's disease and the people who support them.

Across participants, discussions about what the future may look like were very limited, nevertheless the examples provided illustrate the complexity of future outlook and the emotional strain it can bring. Although identity changes in relation to work and driving were discussed more by younger participants, the presence of similar coping strategies across age groups in looking ahead suggests overarching themes, rather than being reduced to age-specific experiences. Importantly, across age groups there appears to be a shared method of managing changing futures: focusing on one day at a time, as discussed in the following global theme.

\section{Maintaining positivity one day at a time}

One of the most prominent findings across the interviews was that despite the difficulties that living with Alzheimer's can bring, participants prioritised staying as positive as possible by taking one day at a time. The findings for this theme have been grouped into three subthemes, 'embracing unpredictability', 'escapism', and 'active avoidance', which will be discussed in turn. 
Future Outlook and Alzheimer's Disease

\section{'Embracing unpredictability'}

One of the first ways participants were able to maintain a positive focus was by separating their circumstances from other's who may be living with the same condition. The unpredictability of Alzheimer's disease and how it progresses was noted across participants, as Isobel (SL5) describes,

“It's different for everyone when it comes; it doesn't necessarily... because aunt went downhill quite quickly." [Whereas, she later describes Oliver's (PL5) condition as slow]. (Isobel, SL5)

Similarly, Jack (PE6) notes a lack of certainty about what might happen,

“I mean you've never ever been out of work, never" (Olivia, SE6). "Nah, this is new to me, know what I mean? What's gonna happen in winter? ... financially I panic, don’t I?" (Jack, PE6).

Many participants felt that it was possible to be too concerned about what may happen in the future. Such unpredictability resulted in participants feeling a lack of control; therefore, they tried not to worry about what could lie ahead as Poppy (SL1) supposed,

"I think you have to shut your mind off to things because I had to think well that might not happen, just the way she'd gone [referring to a book 
Future Outlook and Alzheimer's Disease

character with dementia], that might not necessarily happen so really there is no point dwelling on that." (Poppy, SL1)

Focusing on the present moment helped people to manage the lack of control, as shown by Isobel (SL5) when discussing potential changes in Oliver's (PL5) condition,

"I think once you accept it and stop worrying and imagining what it could be, you just have to take it as it comes." (Isobel)

Despite the lack of control resulting from unpredictable outcomes, the same concept could be used as a source of comfort; as Poppy (SL1) notes,

"You could have a dozen people with Alzheimer's who are all completely different... and they might have come across somebody who's completely different to the next." (Poppy, SL1)

Sophie (SL15) mirrors this,

"You wouldn't get two stories the same" (Sophie, SL15)

Participants were able to reassure themselves that the negative experiences they may have had or known of in others may not be the case for them. 


\section{$\underline{\text { 'Escapism' }}$}

The second sub-theme around 'maintaining positivity one day at a time' was in making space for escapism, exemplified by the fact that when people did look ahead it was for positive reasons such as holidays.

Murray (PE5) had created a bucket list of places he wished to go while he still felt able.

“...This bucket list that started all that in the first place... because it suddenly took me away from what I was...” (Murray, PE5).

Both Murray (PE5) and Lucy (SE5) discussed the various holidays they have managed across the world in recent years,

"So we've done a good bucket list and we've filled a lot of bucket!" (Murray, PE5).

The ability to go away and 'escape' was often framed as being the 'lucky ones' a theme which was seen across findings on future outlook as well as when discussing stigma around Alzheimer's disease (see Ashworth, 2017). For example, Eva (SE1) and James (PE1) discuss the benefits of holidays:

"We're lucky in many ways, we're in a position to be able to do these things, because there are lots of people who, who obviously can't and, perhaps if you're not in a position to be able to, to go on nice holidays and 
Future Outlook and Alzheimer's Disease

you're kind of stuck in worrying about things, that makes things worse..."

(Eva, SE1).

Of note, although people in the late-onset group did discuss holidays as a positive form of escapism there was also a sense of regret for how their holiday patterns had changed, particularly from the perspective of supporters:

"Our holiday taking pattern changed because we used to do a lot of travelling, that has stopped because we weren't going on package holidays, we were just taking off travelling around, and I suddenly realised that we can't do that anymore." (Hamish, SL4)

Age may not be the predominant factor in this however, as the quote from Katie (SE3) demonstrates. Her husband Toby (PE3) with early-onset Alzheimer's disease recently transitioned to a care facility due to Katie struggling to support him alone. Katie's discussion below around holidays suggests that degree of symptoms may be more explanatory than age for the holiday differences noted:

"Going away for a weekend I think the downside of it outweighs the benefits, it's easier not to do it, so, no I wouldn't say the future's looking rosy, I just, there's a lot of regrets, and opportunities lost I think, that's the way I look at it.” (Katie, SE3) 
The experiences of participants highlighted that a positive aspect of early future planning may be to allow people to form a 'bucket list' like Murray's to reduce feelings of regret as the condition progresses. One of the limitations of the joint interviews was that supporters tended to dominate the conversation, although this is not to say people with Alzheimer's disease did not contribute, however, it was more in the form of agreement or part sentences, or other cues. For instance, during the holiday conversation, James (PE2) was keen to share pictures of their excursions and agreed that they help them to 'live well'.

\section{'Active Avoidance'}

The final sub-theme reinforces the idea that there is a deliberate motivation to avoid negativity and focus of positive experiences, achieved through a day at a time perspective. People with Alzheimer's disease and their supporters expressed fear over what the future may hold, yet chose to avoid situations where they may have to confront it, as the following quotes exemplify,

“... The sleepless nights, or you wake early or something, you can, your mind can, you really just try to rein it in and think oh well, nobody knows what's going to happen, so..." (Poppy, SL1)

This can lead to avoidance of activities or more generally choosing not to think about how the future may be, as Lucy (SE5) exemplifies, 
Future Outlook and Alzheimer's Disease

“...There's a great unknown out there, what I do know is there's a lot of variables, and so I could frighten myself to death or not, and I've decided not to frighten myself to death." (Lucy, SE5).

Avoidance to preserve positivity was particularly true for 'dementia support groups': For instance, Poppy (SL1), Emma (SE4) and Lucy (SE5) avoided support groups, fearing meeting people who may have advanced symptoms of Alzheimer's disease. Emma explains,

“There's different types and people are at different stages, and it can be if you're in with a poorer group, oh lord is this what's in front of me? I don't want to be like that, you know?" (Emma, SE4)

This sentiment is mirrored by Poppy (SL1),

"I just feel that groups, I feel personally that that would depress me... but I also feel too that people are obviously going to be at different stages, and also everyone's different, I think I could start to panic, and really worry about the future about things that might never happen." (Poppy, SL1)

From the supporter's perspective, avoidance of future outlook was largely through fear. Cameron (SL10), Poppy (SL1), and Emma (SE4) talked openly and frankly about their fears over not coping with thinking about the future, and wanting to keep their situation at 
a level they could handle. They believed that thinking about a time where things may be worse would lead them to anxiety/depression very quickly, Emma (SE4) summarises the feelings shared by herself, Poppy, and Cameron,

"I couldn't cope with it, literally, you know, our situation just now is at a level I can just handle, you know? I don't know what's going to happen if it gets worse... I just have to take it day by day, week by week, otherwise I'm, I'm sure I would get depressed...not just down in the dumps, I think I could get really, yeah genuinely upset and not able to cope.” (Emma, SE4)

Looking further ahead may compromise the positive focus, and therefore potentially expose people to significant distress. Examples of this can be seen throughout the interviews, such as Cameron's (SL10) fears of looking ahead,

\footnotetext{
"See what happens, not in a position mentally to consider that one, or emotionally." (Cameron, SL10)
}

Conversely, people with Alzheimer's disease such as Jack (PE6) seemingly avoided looking ahead because they did not feel it was necessary,

"I've not done it yet, know what I mean, I've still two arms, two legs." (Jack, PE6) 
Future Outlook and Alzheimer's Disease

Underlying how people with Alzheimer's disease and their supporters look to the future in this study was the way they coped; focusing on the positive as much as possible and taking one day at a time. As Poppy (SL1) exemplifies,

"I think it's just a question of, you know, taking it as it comes, and just hoping that, you know, you can still cope with it.” (Poppy, SL1)

There is a clear acknowledgement and fear towards the future, and therefore in their everyday lives participants focused on dealing with each day at a time. The 'day at a time' way of coping with Alzheimer's disease reinforces the preference for gradual change. For example, Katie (SE3) talked about how she used to make plans but felt this was problematic in hindsight,

"I used to often say to myself, one day at a time, one day at a time, and just try and, I mean I did make some mistakes in maybe forward planning holidays and things that didn't occur, because you really couldn't plan too far ahead..." (Katie, SE3)

Focusing on a day at a time also made it easier to manage plans changing unexpectedly; supported by Holly (SL12) who discussed how you never know whether that plan will end up in place or whether the circumstances will change. As with all of the themes discussed, there is a clear sense that embracing the unpredictable nature of the situation and lack of certainty around what may happen in the near future and distant future is most beneficial to participants. 


\section{Discussion}

The above synthesis of interview data illustrates that people with early and late-onset Alzheimer's disease and their supporters express clear fears about the future and what it may hold. They believed that thinking about a time where things may be worse would lead them to anxiety/depression very quickly; or make feared events more likely to happen. To cope with these fears, participants chose to focus on positive experiences with a deliberate avoidance of negative information; and taking 'one day at a time' to keep their situation manageable. Age of onset of Alzheimer's disease did not seem to change the way people adapted to their futures, although there were age-based differences in terms of how recently occupation and driving status changed. Early research supports that loss of driving license can affect younger people more than older people (Taylor and Tripodes, 2001). Although, this does not mean older people will not be affected by a loss of license (Carr and Ott, 2010).

Other age-related differences in future outlook were present but not consistent in direction. For example, some people affected by early-onset Alzheimer's disease felt they were worse off, having futures 'snatched away' whilst older people with the condition had been able to experience longer without Alzheimer's disease; this finding is in inkeeping with theoretical literature, where people may be adversely affected by events that appear 'off time' to the 'normal' life span (Heckhausen et al., 1989). Comparatively, there were other younger people who felt they were better equipped to deal with the condition due to their age. The alternative responses within and between-groups highlight the subjectivity of experiences and how age does not necessarily separate people with 
Alzheimer's disease as much as the previous literature suggests (Chaston, 2010;

Scodellaro and Pin, 2013). Instead, there was a shared sense of focusing on each day and making the most of the opportunities available.

Socioemotional Selectivity Theory (Carstensen, 1991) predicts that people affected by 'time-limiting' conditions, in this case Alzheimer's disease, will have a similar sense of time being restricted. If Alzheimer's disease were not present, older participants would be expected to have a different view of time to younger participants (Carstensen et al., 1999; Mark, 2012). Whereas, the presence of Alzheimer's disease leads to a shift in focus from knowledge-focused to emotion-focused goals. Overall, this can be seen to influence how younger and older participants managed their experiences. Further support for this finding can be seen in relation to perceived stigma where participants with early and lateonset Alzheimer's disease shared similar coping techniques (Ashworth, 2017). Shared patterns of coping for supporters of people with early and late-onset Alzheimer's disease demonstrates how their futures are interlocking with the person they support, shaping their own sense of time.

The findings of this research reinforce that having Alzheimer's disease does not necessarily mean people cannot look to the future, as hypothesised by some of the neurobiological literature (Addis et al., 2010). Rather, due to awareness of what the future could hold or fear of such circumstances, people chose not to look ahead where possible. Some adjustments were made to people's lives to minimise the potential impact of Alzheimer's disease, such as arranging power of attorney, changing style of holidays and similar activities were organised but 'bracketed-off' (Brown and Graaf, 2013) from 
people's general narrative around 'future outlook'.

Of concern is whether avoiding future planning may be harmful in the long term, despite its short-term benefits. For example, research literature suggests knowledge can lead to increased anxieties (Proctor et al., 2002) and fears for future selves (Kristiansen et al., 2017). Worrying about the future may increase its salience (Szpunar and Schacter, 2013), which would increase fear that it may come to fruition. However, in the long term, not being prepared can lead to significant distress at 'crisis points' (Lockenstoff and Carstensen, 2004; Sinclair et al., 2016). Therefore, greater efforts are needed to support people in looking ahead whilst minimising experiences of distress. It may be that the gateway to this sort of planning is by highlighting the broader nature of future outlook, such as holidays or activity preferences rather than 'care' focus alone.

Future planning from the perspective of current policy and practice was unfamiliar to the majority of people. Choosing not to engage in advance care planning did not seem to be limited to awareness of its existence, or neurological inability to look ahead (Schacter et al., 2013; Addis et al., 2009). Instead consideration of such plans was more intertwined with a shared avoidance of thinking about a feared future. This deliberate diverting of attention to positive stimuli and avoidance of negative events is supported through the theoretical literature and research evidence (Bohn et al., 2016; Kristiensen et al., 2015). For instance, looking too far ahead or acknowledging negative information led people to worry about the future and what may happen. Worrying was seen as unhelpful, particularly as the future was viewed as unpredictable and out of one's control. Therefore, focusing attention on more positive experiences allowed people to maintain a positive emotional state, and manage their everyday experiences. 
If people do not necessarily wish to engage in future planning and instead focus on one day at a time, it may be that the costs of diagnosis such as stigma (Bunn et al., 2012; Iliffe et al., 2003; Milne, 2010) outweigh the proposed benefit of future planning (Dubois et al., 2016). This is supported by recent work into the impact of diagnosis and avoidance of information about the future (Bunn et al., 2012; Lockenhoff and Carstensen, 2004). In contrast, research has highlighted that most people still wish to know their diagnosis (Pinner and Bouman, 2003, Robinson et al., 2011; Robinson et al., 2014) despite the exposure to stigma. Although, these conclusions may be biased, as people who are most fearful of the condition and its anticipated future trajectory may engage less with research.

Considering a time where 'care' needs will increase exposes people to significant distress and activities such as group support are avoided, through fear of seeing people at more 'advanced stages' of their condition. In contrast, there is increasingly positive effects associated with advocacy and the solidarity people with dementia can share in challenging how people view them (Bryden. 2016). As such, support services should be aware of the challenges people face in future outlooks and find ways of helping people to make appropriate plans whilst not compromising their emotional state, and incorporate examples of where support has worked well. Recognising that the view of 'no future' is a stigma-driven assumption (Cowdell, 2014), more accurately represented as a 'changed future' may help to reduce fear of looking ahead. Post-diagnostic support (Scottish Government, 2013; Simmons, 2011) should be tailored to help people acknowledge that it is possible to live well and have a future which is not dominated by 'care', whilst not 
taking away from the challenges people face in learning to live with a condition like Alzheimer's disease.

\section{Limitations}

There are a couple of key limitations to note in relation to the research findings. The conclusions around the perspectives of people with Alzheimer's disease should be taken cautiously given the more in-depth answers were from supporters. All of the participants interviewed for this research also completed a range of questionnaires around perceived stigma (Ashworth, 2017). As a result of this two-part sequential design, there was a gap of between 3-6 months between participants completing questionnaires and later being interviewed about future outlook. Due to the time delay, a couple of the participants with Alzheimer's disease (Toby, PE3 and Millie, PL15) had experienced significant worsening of their symptoms and were not able to engage in the interview based on following process consent (Dewing, 2007). Therefore, their experiences were from the perspective of their supporters only (Katie, SE3 and Holly, S15). Further, on some occasions the person with Alzheimer's disease was present but did not contribute to the interview questions, however, they were included in general conversation so as not to feel excluded. This was the case for Grace (PL2), David (PL1), and Angus (PL15). Overall, this led to 14 interviews, 9 of which were joint, 2 were supporter only and 3 were with limited input from the person with Alzheimer's disease. A shorter delay within the twopart design would potentially have allowed for more in-depth experiences from the person with Alzheimer's disease perspective. Although it could be argued the more cognitively-heavy method of interviews could have been completed as the first part of the sequential design, having contact with the researcher on more than one occasion may have increased trust and openness within the interviews. Research exploring the views of 
a greater number of people with Alzheimer's disease would be beneficial, particularly to see whether the shared coping strategies across age groups remains. Future research may also benefit from separate interviews to help encourage more examples from the person with Alzheimer's diseases perspective, although it should be noted that participants were offered the choice of individual or joint interviews.

Additionally, the study sample is based on Scottish participants who have actively sought to be involved in research. Participation in research has been suggested to foster hope for the future (Black et al., 2008; Karlawish et al., 2001; Sugarman et al., 2001); such hope can play a key role in time-orientation (Brown and Graaf, 2013) and therefore may shape the future outlook. Further, Scotland has a different dementia strategy to the rest of the UK (Scottish Government, 2017), where people diagnosed with dementia are offered one year of post-diagnostic support. Such support may result in different findings elsewhere.

\section{Conclusion}

This article has helped demonstrate the continuous nature of looking to the future.

Participants were seen to think about their immediate futures, and small practical changes, over looking ahead to an 'end point'. Their discussions highlighted that future outlook is not restricted to focusing on 'care'. Rather, it is something that is fluid and changing. How people look to the future can therefore influence the whole journey of dementia, from pre-diagnosis and fears about anticipated futures, through to continuing 'normally' and making the most of the situation you are in. 
Future Outlook and Alzheimer's Disease

One of the consequences of stigma surrounding Alzheimer's disease is people being highly fearful of their future and what may happen. In order to manage fears, people chose to focus on one day at a time, deliberately avoiding planning or looking too far ahead. Alzheimer's disease was viewed by participants as unpredictable and unique, which helped them to manage the lack of control over the condition. The findings are predicted by Socioemotional Selectivity Theory and a range of attributional biases which help people to maintain the positive focus. Overall, there is a need to consider how best to explore the complex nature of future outlook in practice and policy. Of key importance is how to help people affected by Alzheimer's disease remain positive in the face of adversity. In the current context, taking 'one day at a time' appears to be the most adaptive strategy for managing everyday life with Alzheimer's disease, and minimising exposure to stigma-fueled fears of the future.

\section{References}

Abram, M., Picard, L., Navarro, B. and Piolino, P. (2014). Mechanisms of remembering the past and imagining the future - New data from autobiographical memory tasks in a lifespan approach. Consciousness and Cognition, 29, 76-89.

Addis, D. R., Musicaro, R., Pan, L. and Schacter, D. L. (2010). Episodic simulation of past and future events in older adults: Evidence from an experimental recombination task. Psychology and Aging, 25, 369-376.

Addis, D. R., Sacchetti, D. C., Ally, B. A., Budson, A. E. and Schacter, D. L. (2009). Episodic simulation of future events is impaired in mild Alzheimer's disease.

Neuropsychologia. 47, 2660-2671. 
Future Outlook and Alzheimer's Disease

Ashworth, R. (2014). More than just a cup of tea: Everyday cultural practices and interactions in research. Generations Review, 24, 4-10.

Ashworth, R. (2017). Perceptions of stigma among people affected by early and lateonset Alzheimer's disease. Journal of Health Psychology, 1-21.

Bryman, A., Becker, S. and Sempik, J. (2008). Quality criteria for quantitative, qualitative and mixed methods research: A view from social policy. International Journal of Social Research Methodology, 11, 261-276.

Benbow, S. M. and Jolley, D. (2012). Dementia: Stigma and its effects.

Neurodegenerative Disease Management, 2, 165-172.

Bohn, L., See, S. T. K. and Fung, H. H. (2016). Time perspective and positivity effects in Alzheimer's disease. Psychology and Aging, 31, 574-582.

Black, B., Brandt, J., Rabins, P. V., Samus, Q. M., Stelle, C. D., Lykestsos, C. G. and Rosenblatt, A. (2008). Predictors of providing informed consent or assent for research participation in assisted living residents. American Journal of Geriatric Psychiatry, 16, 83-91.

Braun, V. and Clarke, V. (2006). Using thematic analysis in psychology. Qualitative Research in Psychology, 3, 77-101.

Brodaty, H. and Donkin, M. (2009). Family caregivers of people with dementia. Dialogues of Clinical Neuroscience, 11, 217-228., Brown, P. and Graaf, S. (2013). Considering a future which may not exist: the construction of time and expectations amidst advanced-stage cancer. Health, Risk and Society, 15, 543-560.

Bryden, C. (2016). Nothing about us, without us! 20 years of dementia advocacy. London: Jessica Kingsley Publishers. 
Future Outlook and Alzheimer's Disease

Buckner, R. L. and Carroll, D. C. (2007). Self-projection and the brain. Trends in Cognitive Science. 11, 49-57.

Bunn, F., Goodman, C., Sworn, K., Rait, G., Brayne, C., Robinson, L., McNeilly, E. and Iliffe, S. (2012). Psychosocial factors that shape patient and carer experiences of dementia diagnosis and treatment: A systematic review of qualitative studies. PLOS Medicine, 9: e1001331.

Carr, D. B. and Ott, B. R. (2010). The older adult driver with cognitive impairment "it's a very frustrating life”. JAMA, 303, 1632-1641.

Carstensen, L. L. (1991). Selectivity theory: Social activity in life-span context. Annual Review of Gerontology and Geriatrics, 11, 195-217.

Carstensen, L. L., Isaacowitz, D. M. and Charles, S. T. (1999). Taking time seriously: A theory of socioemotional selectivity. American Psychologist, 54, 165-181.

Chaston, D. (2010). Younger adults with dementia: A strategy to promote awareness and transform perceptions. Contemporary Nurse, 34, 221-229.

Chenoweth, L., King, M. T., Jeon, Y-H., Brodaty, H., Stein-Parbury, J., Norman, R., Hass, M. and Luscombe, G. (2009). Caring for aged dementia care resident study (CADRES) of person-centred care, dementia-care mapping, and usual care in dementia: A cluster-randomised trial. The Lancet Neurology, 8, 317-325.

Cowdell, F. (2014). “That's How We Do It... We Treat Them All The Same.”: An Exploration of the Experiences of Patients, Lay Carers and Health and Social Care Staff of the Care Received by Older People with Dementia in Acute Hospital Settings. Cambridge: Cambridge Scholars Publishing.

De Vito, S., Gamboz, N. and Brandimonte, M. A. (2012). What differentiates episodic future thinking from complex scene imagery? Conscious Cognition, 21, 813-823. 
Future Outlook and Alzheimer's Disease

Department of Health. (2009). Living Well with Dementia: A National Dementia

Strategy. Available at:

https://assets.publishing.service.gov.uk/government/uploads/system/uploads/attachment data/file/168220/dh_094051.pdf [Accessed 26 April 2018]

Department of Health. (2015). Prime Minister's Challenge on Dementia 2020. London:

Williams Lea. Available at:

https://www.gov.uk/government/uploads/system/uploads/attachment_data/file/414344/p m-dementia2020.pdf [Accessed 26 April 2018].

Dewing, J. (2007). Participatory research: A method for process consent with persons who have dementia. Dementia, 6, 11-25.

Doody, R. S., Pavlik, V., Massman, P., Rountree, S., Darby, E. and Chan, W. (2010). Predicting progression of Alzheimer's disease. Alzheimer's Research and Therapy, 2, 210.

Dubois, B., Padovani, A., Schletens, P., Rossi, A. and Dell'Agnello, G. (2016). Timely diagnosis for Alzheimer's disease: A literature review on benefits and challenges. Journal of Alzheimer's Disease, 49, 617-631.

Entwistle, V. A. and Watt, I. S. (2013). Treating patients as persons: A capabilities approach to support delivery of person-centered care. The American Journal of Bioethics, 13, 29-39.

Feldman, H., Van Baelen, B., Kavanagh, S. M. and Torfs, K. E. L. (2005). Cognition, function, and caregiving time patterns in patients with mild-to-moderate Alzheimer's disease: A 12-month analysis. Alzheimer's Disease and Associated Disorders, 19, 29-36. Gillies, B. and Johnston, G. (2004). Identity loss and maintenance: Commonality of experience in cancer and dementia. European Journal of Cancer Care, 13, 436-442. 
Heckhausen, J., Dixon, R. A. and Baltes, P. B. (1989). Gains and losses in development throughout adulthood as perceived by different adult age groups. Developmental Psychology, 25, 109-121.

Hicks, J. A., Davis, W. E., Trent, J. and King, L. A. (2012). Positive affect, meaning in life, and future time perspective: An application of Socioemotional Selectivity Theory. Psychology and Aging, 27, 181-189.

Higgins, P. (2013). Involving people with dementia in research. Nursing Times, 109), 2023.

Iliffe, S., Manthorpe, J., and Eden, A. (2003). Sooner or later? Issues in the early diagnosis of dementia in general practice: A qualitative study. Family Practice, 20, 376381.

Jalbert, J. J., Daiello, L. A. and Lapane, K. L. (2008). Dementia of the Alzheimer type. Epidemiologic Reviews, 30, 15-34.

Karg, N., Graessal, E., Randzio, O. and Pendergrass, A. (2018). Dementia as a predictor of care-related quality of life in informal caregivers: A cross-sectional study to investigate differences in health-related outcomes between dementia and non-dementia caregivers. BMC Geriatrics, 18, 1-9.

Karlawish, J. H., Casarett, D., Klocinski, J. and Sankar, P. (2001). How do AD patients and their caregivers decide whether to enroll in a clinical trial? Neurology, 56, 789-792. Kirshbaum, M. N. Y., Carey, I., Purcell, N. and Nash. S. (2011). Talking about dying and death: a focus group study to explore a local community perspective. Nursing Reports, 1 , 29-34.

Koedam, E. L. G. E., Lauffer, V., Van der Vlies, A. E., Van der Flier, W. M., Scheltens, P. and Pijnenburg, Y. A. L. (2010). Early-versus late-onset Alzheimer's disease: More than age alone. Journal of Alzheimer's Disease, 19, 1401-1408. 
Kristiansen, P. J. L., Normann, H. K., Norberg, A., Fjelltun, A-M. and Skaalvik, M. W. (2017). How do people in the early stage of Alzheimer's disease see their future?

Dementia, 16, 145-157.

Livingston, G., Leavey, G., Manela, M., Livingston, D., Rait, G., Sampson, E., Bavishi, S., Shahriyamolki, K. and Cooper, C. (2010). Making decisions for people with dementia who lack capacity: qualitative study of family carers in UK. BMJ, 341, c4184.

Lockenhoff, C. E. and Carstensen, L. L. (2004). Socioemotional Selectivity Theory, aging and health: The increasingly delicate balance between regulating emotions and making tough choices. Journal of Personality, 72, 1395-1424.

Mark, R. E. (2012). Understanding the individual with Alzheimer's disease: Can Socioemotional Selectivity Theory guide us? Advances in Alzheimer's Disease, 1, 77-86. Mason, M. (2010). Sample size and saturation in PhD studies using qualitative interviews. 11, 1-19.

McParland, P., Devine, P., Innes, A. and Gayle, V. (2012). Dementia knowledge and attitudes of the general public in Northern Ireland: An analysis of national survey data. International Psychogeriatrics, 24, 1600-1613.

Milne, A. (2010). The 'D' word: Reflections on the relationship between stigma, discrimination and dementia. Journal of Mental Health, 19, 227-233.

Molyneaux, V., Butchard, S., Simpson, J. and Murray, C. (2011). Reconsidering the term 'carer': a critique of the universal adoption of the term 'carer'. Ageing and Society, 31, $422-437$.

Moravcsik, A. (2014). Transparency: The Revolution in Qualitative Research. PS: Political Science and Politics, 47, 48-53.

NVivo qualitative data analysis Software; QSR International Pty Ltd. Version 10, 2012. 
O’Connor, D. (2007). Self-identifying as a caregiver: exploring the positioning process. Journal of Aging Studies, 21, 165-174.

Pinner, G. and Bouman, W. P. (2003). Attitudes of patients with mild dementia and their carers towards a disclosure of the diagnosis. International Psychogeriatrics, 15, 279-288. Poole, M., Bamford, C., McLellan, E., Lee, R. L., Exley, C., Hughes, J. C., HarrisonDening, K. and Robinson, L. (2018). End-of-life care: A qualitative study comparing the views of people with dementia and family carers. Palliative Medicine, 32, 631-642 Pot, A. M. and Petrea, I. (2013). Bupa/ADI Report: Improving Dementia Care Worldwide: Ideas and Advice on Developing and Implementing a National Dementia Plan. London: Bupa/ADI.

Proctor, R., Martin, C. and Hewison, J. (2002). When a little knowledge is a dangerous thing...: A study of carers' knowledge about dementia, preferred coping style and psychological distress. International Journal of Geriatric Psychiatry, 17, 1133-1139. Ramsbottom, K. and Kelley, M. L. (2014). Developing strategies to improve advance care planning in long term care homes: Giving voice to residents and their family members. International Journal of Palliative Care. Available at: https://www.hindawi.com/archive/2014/358457 [Accessed 26 April 2018]. Robinson, S. M., Canavan, M. and O’Keeffe, S. T. (2014). Preferences of older people for early diagnosis and disclosure of Alzheimer's disease (AD) before and after considering potential risks and benefits. Archives of Gerontology and Geriatrics, 59, 607612.

Robinson, L., Gemski, A., Abley, C., Bond, J., Keady, J., Campbell, S., Samsi, K. and Manthorpe, J. (2011). The transition to dementia- individual and family experiences of receiving a diagnosis: a review. International Psychogeriatrics, 23, 1026-1043. 
Future Outlook and Alzheimer's Disease

Samsi, K. and Manthorpe, J. (2014). Care pathways for dementia: Current perspective. Clinical Interventions in Aging, 9, 2055-2063.

Schacter, D.L. and Addis, D.R. (2007). The cognitive neuroscience of constructive memory: remembering the past and imagining the future. Philosophical Transactions of the Royal Society B: Biological Sciences, 362, 773-786.

Schacter, D. L., Addis, D. R. and Buckner, R. L. (2007). Remembering the past to imagine the future: the prospective brain. Neuroscience, $8,657-661$.

Schacter, D. L., Gaesser, B. and Addis, D. R. (2013). Remembering the past and imagining the future in the elderly. Gerontology, 59, 143-151.

Scodellaro, C. and Pin, S. (2013). The ambiguous relationships between aging and Alzheimer's disease: A critical literature review. Dementia (London), 12, 137-151. Scottish Government. (2013). Scotland's National Dementia Strategy 2013-2015. Available at: http://www.gov.scot/Topics/Health/Services/Mental-

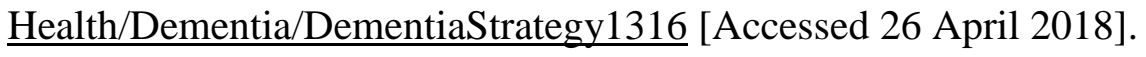
Scottish Government. (2017). Scotland's National Dementia Strategy 2017-2020. Available at: http://www.gov.scot/Publications/2017/06/7735 [Accessed 16th April 2018] Sharot, T. (2011). The optimism bias. Current Biology, 21, 941-945.

Simmons, H. (2011). Getting Post-Diagnostic Support Right for People with Dementia. Available at: http://www.alzscot.org./assets/0001/1226/Getting_post_diagnostic_support_right.pdf [Accessed 26 April 2018].

Sinclair, J, B., Oyebode, J. R., and Owens, R. G. (2016). Consensus views on advance care planning for dementia: A Delphi study. Health and Social Care in the Community, 24, 165-174. 
Small, N. and Rhodes, P. (2001). User Involvement and the Seriously Ill. Available at: http://www.jrf.org.uk/publications/user-involvement-and-seriously-ill [Accessed 28th October 2018].

Sugarman, J., Cain, C., Wallace, R. and Welsh-Bohmer, K. A. (2001). How proxies make decisions about research for patients with Alzheimer's disease. Journal of the American Geriatrics Society, 49, 1110-1119.

Szpunar, K. K. and Schacter, D. L. (2013). Get real: Effects of repeated simulation and emotion on the perceived plausibility of future experiences. Journal of Experimental Psychology General, 142, 323-327.

Taylor, B. D. and Tripodes, S. (2001). The effects of driving cessation on the elderly the dementia and their caregivers. Accident Analysis and Prevention, 33, 519-528.

Tulving, E. (2005). Episodic memory and autonoesis: uniquely human? In: H. S. Terrace and J. Metcalfe. (eds.) The Missing Link in Cognition: Origins of Self-reflective Consciousness. New York: Oxford University Press, 3-56.

Vaismoradi, M., Jones, J., Turunen, H. and Snelgrove, S. (2016). Theme development in qualitative content analysis and thematic analysis. Journal of Nursing Education and Practice, 6, 100-110. 